\title{
Design and performance of an automatic regenerating adsorption aerosol dryer for continuous operation at monitoring sites
}

\author{
T. M. Tuch, A. Haudek, T. Müller, A. Nowak, H. Wex, and A. Wiedensohler \\ Leibniz Institute for Tropospheric Research, Leipzig, Germany
}

Received: 9 April 2009 - Published in Atmos. Meas. Tech. Discuss.: 23 April 2009

Revised: 22 July 2009 - Accepted: 23 July 2009 - Published: 30 July 2009

\begin{abstract}
Sizes of aerosol particles depend on the relative humidity of their carrier gas. Most monitoring networks require therefore that the aerosol is dried to a relative humidity below $50 \%$ r.H. to ensure comparability of measurements at different sites. Commercially available aerosol dryers are often not suitable for this purpose at remote monitoring sites. Adsorption dryers need to be regenerated frequently and maintenance-free single column Nafion dryers are not designed for high aerosol flow rates. We therefore developed an automatic regenerating adsorption aerosol dryer with a design flow rate of $1 \mathrm{~m}^{3} / \mathrm{h}$. Particle transmission efficiency of this dryer has been determined during a 3 week experiment. The lower $50 \%$ cut-off was found to be smaller than $3 \mathrm{~nm}$ at the design flow rate of the instrument. Measured transmission efficiencies are in good agreement with theoretical calculations. One dryer has been successfully deployed in the Amazon river basin. We present data from this monitoring site for the first 6 months of measurements (February 2008-August 2008). Apart from one unscheduled service, this dryer did not require any maintenance during this time period. The average relative humidity of the dried aerosol was $27.1+/-7.5 \%$ r.H. compared to an average ambient relative humidity of nearly $80 \%$ and temperatures around $30^{\circ} \mathrm{C}$. This initial deployment demonstrated that these dryers are well suitable for continuous operation at remote monitoring sites under adverse ambient conditions.
\end{abstract}

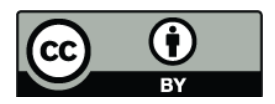

Correspondence to: T. M. Tuch (tuch@tropos.de)

\section{Introduction}

Diameters of aerosol particles, and thereby their physical and optical properties, depend on the relative humidity of the carrier gas (e.g. Mozurkewich, 1986; Ten Brink et al., 2000; Wex et al., 2006). To investigate aerosol effects on climate it would be desirable to measure physical and optical properties at ambient relative humidity. This would either require avoiding any temperature (and thereby relative humidity) change during the transport from ambient air to the measurement volume or the reconditioning of the aerosol to ambient relative humidity prior to the measurement. The latter approach has been implemented in research grade instruments such as the Hygroscopicity Tandem Differential Mobility Analyzer (HTDMA) but most commercially available instruments used at monitoring sites are not designed to preserve atmospheric humidity conditions (e.g. due to internal heating by electronic components). In many instruments, the reduction of relative humidity is even desired to avoid condensation of water vapour on internal surfaces. Consequently, in the past, comparison of aerosol parameters from different measurement sites with different humidity conditions has been difficult.

With the establishment of major measurement networks like the Global Atmosphere Watch (GAW) program of the World Meteorological Organization (WMO) or the European Supersites for Atmospheric Aerosol Research (EUSAAR) and many others this problem needed to be solved. Because significant aerosol growth typically starts at relative humidity levels greater than about $50 \%$, a common approach is to measure the aerosol below this threshold level (Baltensperger et al., 2003). The philosophy is therefore to conduct the measurements at low relative humidity conditions to be comparable between different sampling sites. Especially under warm and humid conditions active drying of the aerosol is necessary to achieve this goal.

Published by Copernicus Publications on behalf of the European Geosciences Union. 


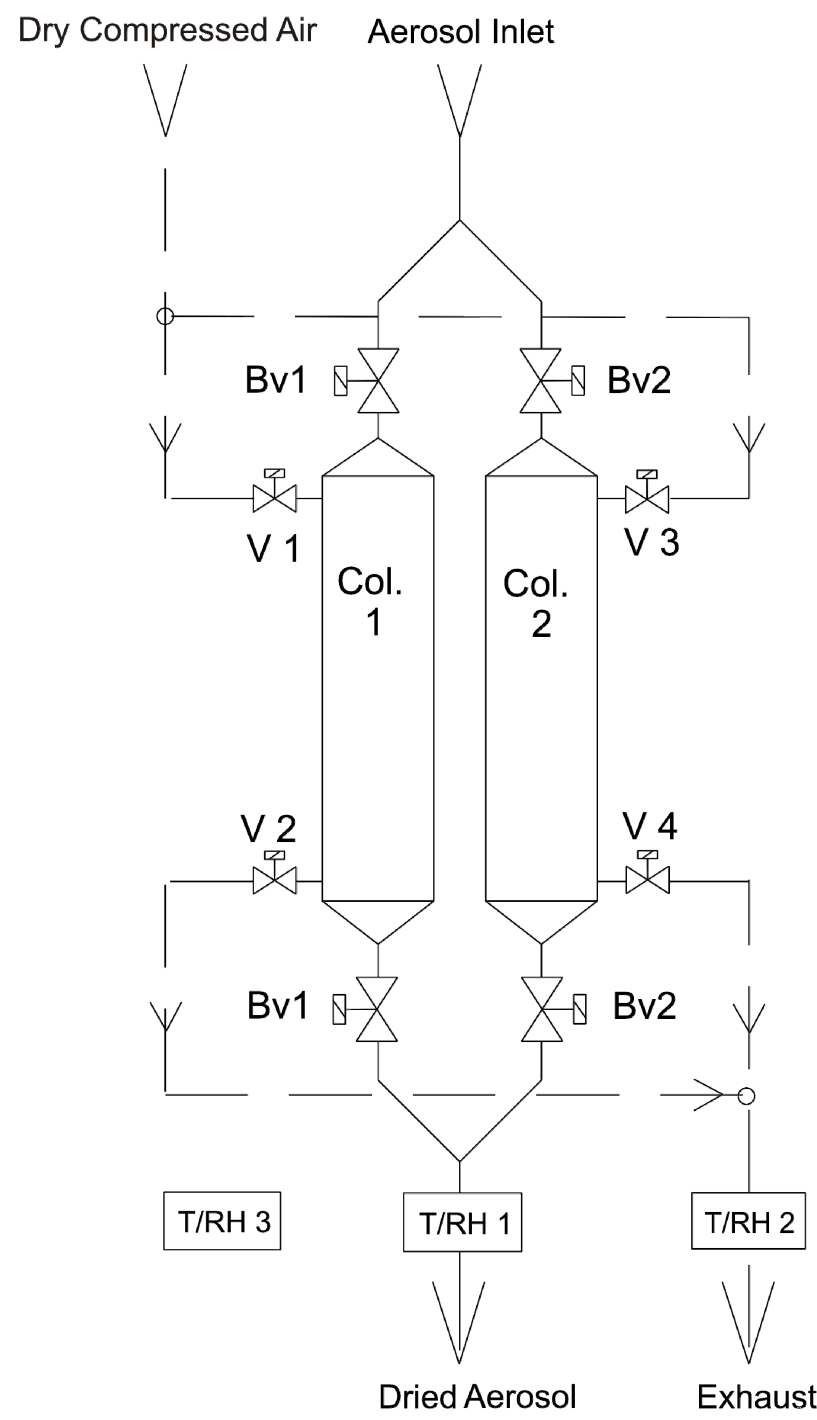

Fig. 1. Schematic view of the aerosol dryer.

Currently three methods are used to condition the aerosol to the required relative humidity.

A first approach is to heat aerosol, although the temperature must be kept low to minimize evaporation, e.g. up to $20 \%$ of ammonium nitrate evaporates from the aerosol within $5 \mathrm{~s}$ at a temperature of 42 degrees Celsius (Bergin et al., 1997). Losses at 50 degrees Celsius were observed comparing filter based measurements with TEOM derived mass concentrations (Cyrys et al., 2001, Charron et al., 2004). This method of aerosol drying is therefore primarily suitable for cold and dry regions, where mild heating at $30^{\circ} \mathrm{C}$ is sufficient to condition the aerosol to the required relative humidity.

Presently, semi-permeable tubes (Nafion, Wilmington, DE or Gore-Tex, W. L. Gore and Associates, Newark, DE) are used for aerosol drying. Because of the small diameter of commercially available single Nafion tubes these dryers are only suitable for aerosol flow rates up to $2 \mathrm{l} / \mathrm{min}$. They should not be used at higher flow rates to avoid turbulent deposition of particles in the dryer. Commercially available bundles of 50-100 single Nafion tubes, capable of handling higher flow rates, are designed to dry gases. Used for aerosol drying, these dryers suffer from impaction losses on the faceplate of the bundles, and a pressure drop of several 10th of $\mathrm{hPa}$ depending on the flow rate. Gore-Tex dryers with larger inner diameters can be built avoiding this restriction of commercially available Nafion dryers. Gore-Tex dryers need a constant dry air supply of at least twice the aerosol flow to maintain a relative humidity of the aerosol of less than $50 \%$. Unlike chemical absorbents Gore-Tex dryers do not have a buffering capacity. Such a buffering capacity would, however, be desirable for aerosol dryers to smoothen fast fluctuations of the relative humidity of the ambient aerosol.

Diffusion dryers using chemical adsorbents such as Silica gel are designed specifically designed for the minimization of aerosol losses at high flow rates. In these dryers, the chemical adsorbent needs to be exchanged and regenerated on a regular basis. Often this is not feasible at remote monitoring sites that are not permanently manned.

We therefore developed an automatically regenerating chemical adsorption dryer for long-term measurements of aerosol properties. Here, we present the design and performance of this automated aerosol diffusion dryer.

\section{Design and operation of the automated aerosol diffusion dryer}

The aerosol dryer is housed in a separate shelter which can be deployed on the roof of a measurement laboratory. This shelter may either be air conditioned or kept at laboratory temperature by active ventilation from the laboratory. All parts of the dryer in contact with the aerosols are made of stainless steel. Non-conducting surfaces that support surface and body charges have been avoided to prevent unwanted fields arising from tribo, piezo or other charging activity (that are slow to dissipate). Stationary electric fields would increase losses of particles due to electrostatic deposition. All aerosol ducts are optimized for minimal losses at an aerosol flow rate of $1 \mathrm{~m}^{3} / \mathrm{h}$. For this purpose, $3 / 4^{\prime \prime}$ tubing with minimal bends is used for aerosol ducts outside the dryer columns. A scheme of the dryer is shown in Fig. 1. The whole assembly consisting of the dryer and the shelter weighs about $160 \mathrm{~kg}$.

Aerosol enters the shelter through a commercially available $\mathrm{PM}_{10}$ inlet. Subsequently, it is fed to one of two parallel stainless steel columns with an inner diameter of $70 \mathrm{~mm}$ and a total length of $800 \mathrm{~mm}$. Each of these columns if filled with approximately $11 \mathrm{~kg}$ of Silica gel and houses seven aerosol ducts made of stainless steel mesh (wire diameter $0.25 \mathrm{~mm}$, open area $0.4 \mathrm{~mm}^{2}$ ) with an inner diameter of $10 \mathrm{~mm}$. The calculated residence time of the aerosol in the columns is $1.6 \mathrm{~s}$ at a flow rate of $1 \mathrm{~m}^{3} / \mathrm{h}$. In operation, one of these 
columns is used for aerosol drying, while the other column is regenerated at ambient pressure by dry air, with a very low dew point temperature, supplied by a large compressor. For this purpose, each column can be shut at the top and bottom by motor actuated ball valves Bv1 or Bv2 (EKN 3/4-020-L020, Bahr GmbH, Dattenberg, Germany). These ball valves feature a straight $3 / 4^{\prime \prime}$ bore to minimize aerosol losses. During regeneration, the dry air is flushed through the column separated from the atmosphere using the magnetic valves V1/2 or V3/4 respectively (type 6013, Christian Bürkert $\mathrm{GmbH}$ and $\mathrm{Co}$. KG, Ingelfingen, Germany).

For our deployment, we use a scroll compressor with active water removal (Mark 3 OFMS 2SD, MET Technology Ltd, Stockport, Great Britain) providing up to $14.4 \mathrm{~m}^{3} / \mathrm{h}$ of dry air for the regeneration of the Silica gel. The dew point temperature of the air is additionally reduced by an automatic adsorption dryer (DAZ5, Boge Int. GmbH, Bielefeld, Germany).

The temperature and relative humidity of the dried aerosol, the currently regenerating column, and the shelter are constantly measured by $3 \mathrm{RH} / \mathrm{T}$ sensors (HIH-4602-C, HyCal Sensing Products, El Monte, CA) using a National Instruments data acquisition board type USB-6009 (National Instruments, Austin, TX). Analog output signals from this board are used to drive the actuators of the valves. Operation of the aerosol dryer is controlled by a custom made LabView program (LabView 8.5, National Instruments, Austin, TX). A flow diagram of the control program is shown in Fig. 2.

This program initiates a column switch if the set-point for the aerosol humidity is exceeded and the last change of the columns has exceeded the set minimum time. This time has been implemented to avoid extensive switching of the columns. When a column change is initiated the magnetic feed valves $(\mathrm{V} 1, \mathrm{~V} 3)$ for the dry air are closed first. Then both magnetic exhaust valves (V2, V4) are opened to avoid any pressure change in the aerosol line after the dryer. In the next step, the ball valves of the freshly regenerated column are opened (BV1 or BV2). Only after these ball valves are fully open the ball valves of the used column (BV2 or $\mathrm{BV} 1)$ are closed, its magnetic exhaust valve (V2 or V4) is opened and the feed valve (V1 or V2) is opened starting the regeneration process. This sequence minimizes dilution effects during column change and avoids pressure fluctuations, which would cause unwanted peaks in filter based aerosol measurements.

Temperature and humidity values measured by all sensors are logged every $10 \mathrm{~min}$ along with information on the column in use. An additional record is written after each column change.

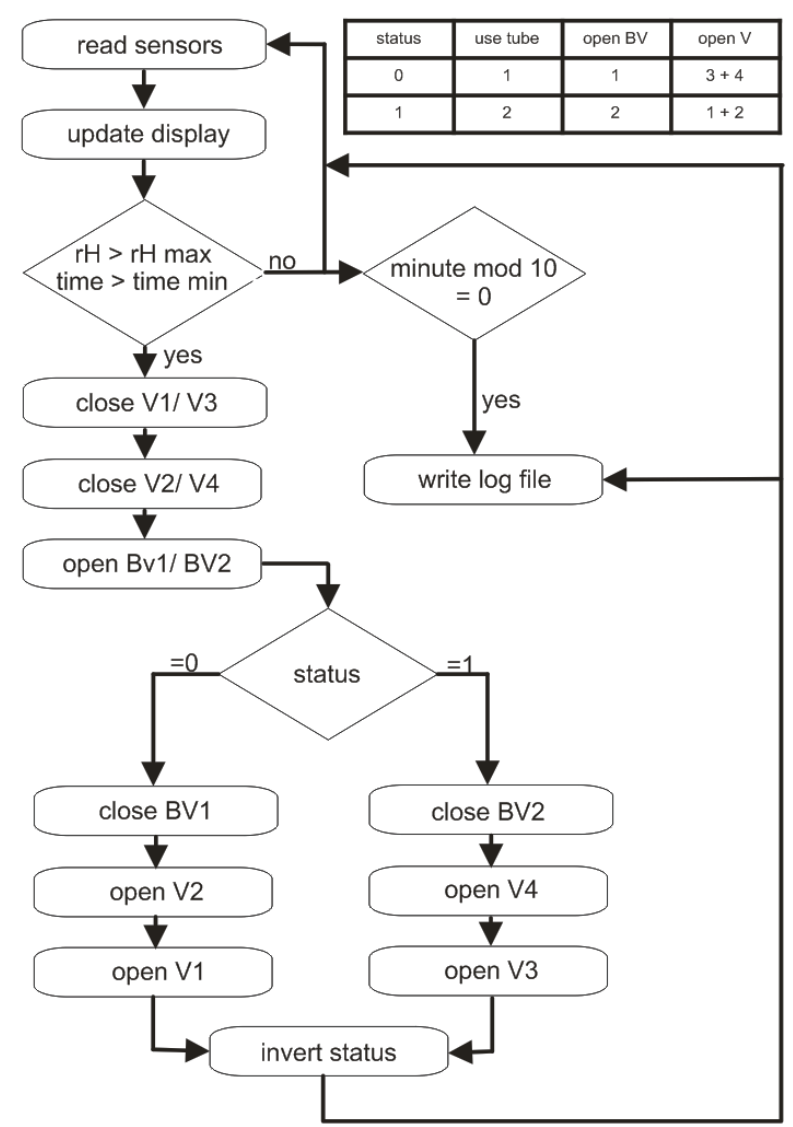

Fig. 2. Flow diagram of the control program for the dryer.

\section{Performance}

\subsection{Aerosol losses in the dryer}

A major concern in the design of an aerosol dryer is minimization of aerosol losses in the system. The design of this dryer has been optimized towards this goal. We measured particle losses under ambient conditions during a 3 week field campaign in Melpitz, Germany. During this campaign, we attached a vertical 3/4" inlet tube and the aerosol dryer to the same Twin DMPS system (Birmilli et al., 1999) measuring the number size distribution in the size range from 3 to $800 \mathrm{~nm}$. Both inlets were equipped with commercially available $\mathrm{PM}_{10}$ sampling heads and operated at an aerosol flow rate of $1 \mathrm{~m}^{3} / \mathrm{h}$. Automatic ball valves were used to switch between both inlets after each 10 min measurement of one number size distribution. The dryer columns were filled with Silica gel. An additional Nafion dryer was mounted at the inlet of the TDMPS to avoid artifacts due to the different relative humidity of both aerosol paths.

Three week average raw particle number size distributions measured during this experiment with and without aerosol dryer are shown in Fig. 3. The blue circles represent the average raw concentrations per size channel without aerosol 


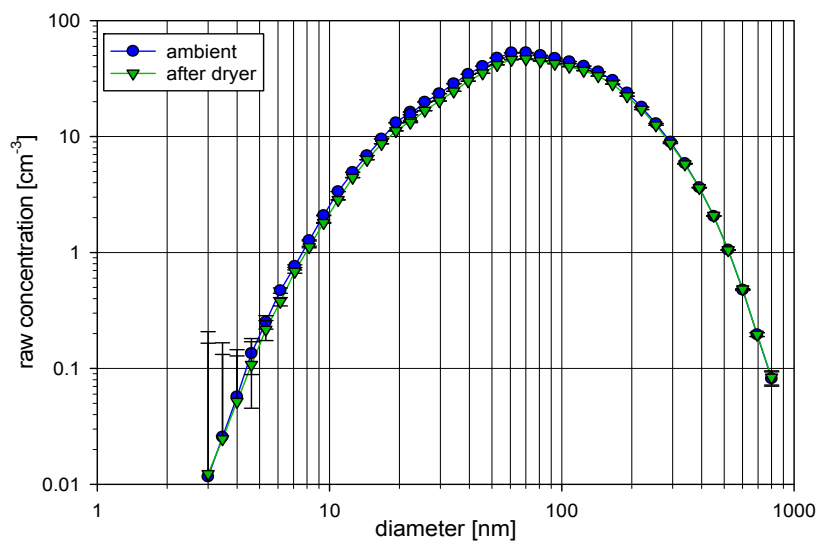

Fig. 3. Average size distribution during field intercomparison.

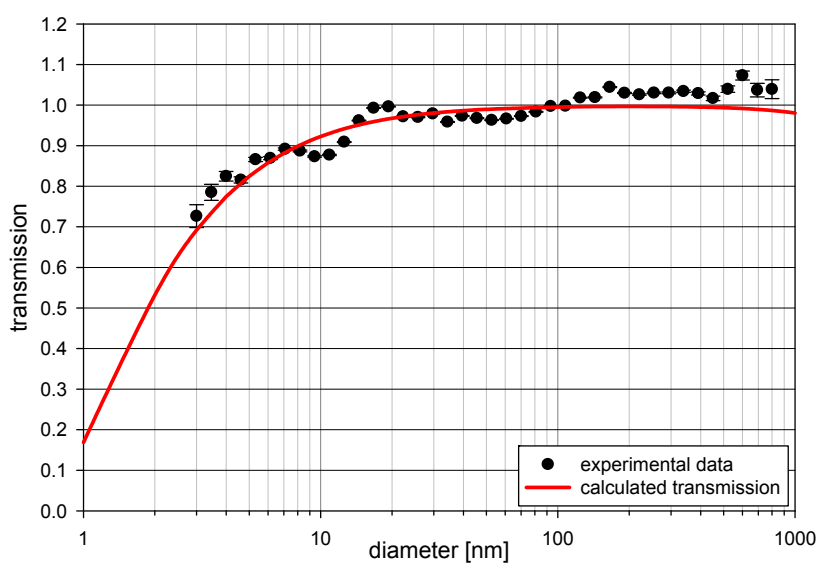

Fig. 4. Size dependent transmission of the aerosol dryer (measured and calculated) at $16.7 \mathrm{l} / \mathrm{min}$.

dryer, the green triangles represent the respective measurements with the aerosol dryer. Errors bars shown in this figure are Poisson errors due to counting statistics (+/-1 Std. Dev).

Figure 4 presents the transmission efficiency of the aerosol dryer derived from these number size distributions. Here, the black dots represent the actual measurements along with their Poisson error. The additional red curve shows the calculated transmission efficiency including diffusion, sedimentation and impaction losses (Baron and Willeke, 2001). Measured and calculated transmissions are in good agreement for the flow rate of $1 \mathrm{~m}^{3} / \mathrm{h}\left(R^{2}=0.96\right)$ used in this experiment. Transmission efficiencies exceeding 1 are due to different tube lengths of both inlets and to non ideal external plumbing due to the limited space in the measurement container.

We found a transmission efficiency of $72 \%$ for $3 \mathrm{~nm}$ particles increasing to $92 \%$ for $10 \mathrm{~nm}$ particles. The lower $50 \%$ penetration diameter was below at $3 \mathrm{~nm}$. Losses of particles larger than $800 \mathrm{~nm}$ could not be determined in this experiment. Calculated losses for larger particles in the dryer suggest an upper $50 \%$ penetration diameter of $6000 \mathrm{~nm}$.

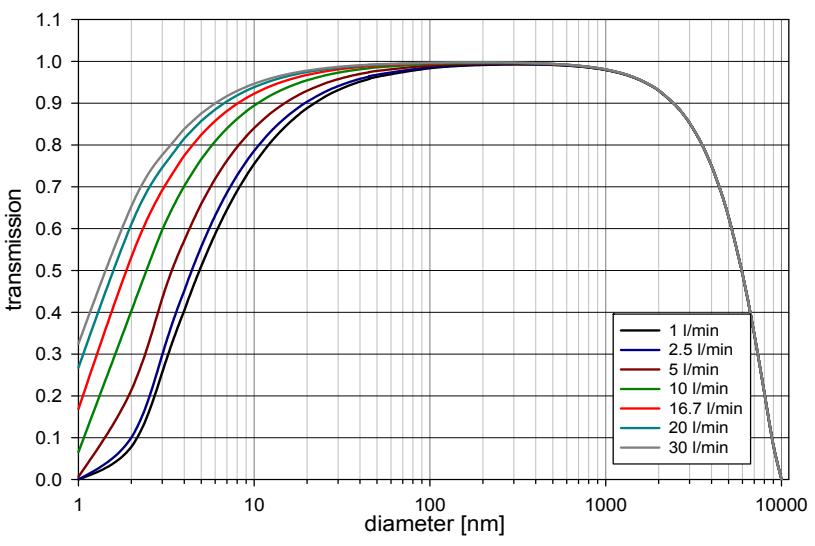

Fig. 5. Size dependent transmission of the dryer, calculated curves for air flow rates from 1 to 30 1/min.

Based on this experiment, we calculated transmission efficiencies for different aerosol flow rates (Fig. 5). The lowest usable flow rate with a penetration efficiency of $50 \%$ for $3 \mathrm{~nm}$ particles was found between $51 / \mathrm{min}$ and $101 / \mathrm{min}$. Lower flow rates should only be used with this dryer if nano-particles are not being measured. With increasing aerosol flow rate, the lower penetration diameter shifts towards smaller particles shifts towards smaller particles but at the expense of decreased drying performance.

\subsection{Drying performance}

So far seven dryers of this type are deployed world-wide. One of the most challenging sites for such an instrument is located in the rainforest of the Amazon river basin about $50 \mathrm{~km}$ from the city of Manaus. Typical monthly average temperatures at this site range from 24 to 33 degrees Celsius with a daily average relative humidity of up to $90 \%$.

The first dryer was installed at this site in the context of the European Integrated project on Aerosol Cloud Climate and Air Quality Interactions (EUCAARI). The average ambient temperature from February 2008 through August 2008 was $30.3+/-2.3$ degrees Celsius with a relative humidity of $78.5+/-3.9 \%$. The actual relative humidity of the ambient aerosol was even higher because the "ambient" humidity sensor is mounted inside the shelter of the dryer. There exhaust air from the regeneration process of the columns is used to lower the humidity inside the shelter in order to protect the electronics of the system from water condensation.

During the experiment, the average relative humidity of the dried aerosol was $27.1+/-7.5 \%$. The time series of the dried aerosol (red) and of the humidity inside the shelter (orange) during this experiment is shown in Fig. 6. Missing data in March 2008 were due to a compressor failure caused by overheating. To avoid such failures the compressor housing has been modified and can now be actively ventilated. A closer examination of the time series of relative humidity 


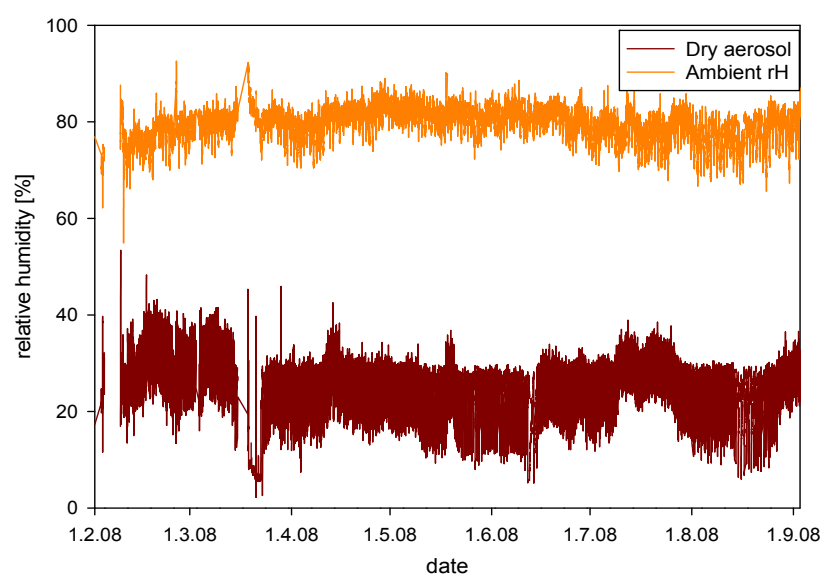

Fig. 6. Dryer performance at Manaus station.

(Fig. 7) with target aerosol humidity set to $30 \%$ reveals that in the beginning the dryer was operating close to its design limits. The columns were switched every $60 \mathrm{~min}$ (set minimum time) but this time was not sufficient to finish the drying process of the regenerating column. Nevertheless, aerosol humidity stayed well below $50 \%$ throughout the whole time period. To avoid operation of the dryer close to its limits the set-point for the target humidity was increased to $40 \%$ and minimum time between column changes was increased to $120 \mathrm{~min}$ allowing for better drying of the columns during regeneration. After these changes, the dryer performed well and we did not encounter further problems with its drying capacity.

All other aerosol dryers, deployed in less challenging environments, have performed as well or better. There was no scheduled maintenance during the time period of 6 months. Some unscheduled repair and modification was, however, necessary because of the overheating of the compressor. After 16 months the dryer at the Manaus site is still running with the first load of Silica gel. A zero filter is used monthly to detect possible contamination of the aerosol due to degradation of the adsorbent.

\section{Summary and conclusions}

We have designed a new automatically regenerating aerosol diffusion dryer that performs well under adverse environmental conditions. The relative humidity of the aerosol at the most challenging site never exceeded design values. The operating parameters of the drying system need to be set to the specific site requirements, but little routine maintenance is required making it ideal for use at remote continuous monitoring sites. Aerosol losses in the system were measured using atmospheric aerosol. Observed transmission efficiencies agree well with theoretical calculated values. Operated at the design flow rate, aerosol penetration efficiency reaches ap-

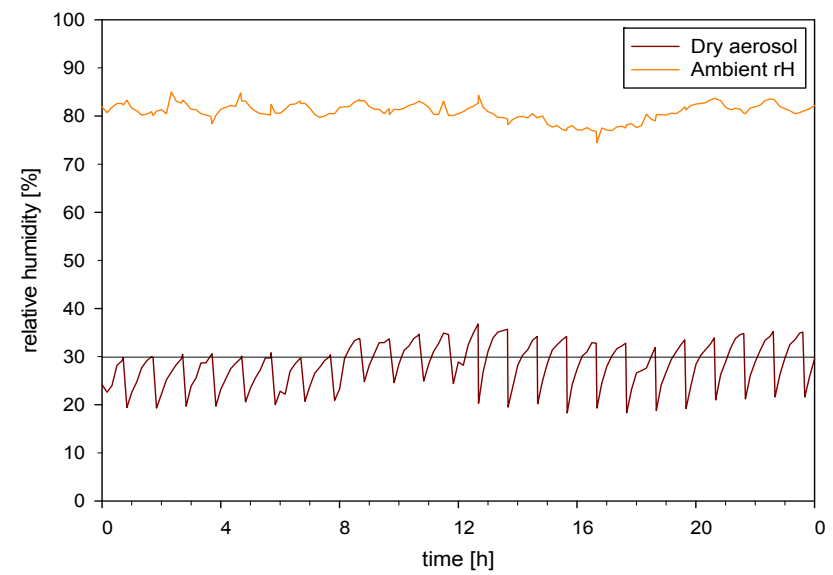

Fig. 7. Diurnal variation of ambient and aerosol humidity in the Amazon basin. (Example 13 April 2008 with dryer at design limits around noon).

proximately $100 \%$ over the size range from $20 \mathrm{~nm}$ to $800 \mathrm{~nm}$. The lower 50\% penetration diameter was smaller than $3 \mathrm{~nm}$ at the design flow rate of $1 \mathrm{~m}^{3} / \mathrm{h}$, while the calculated upper value is around $6000 \mathrm{~nm}$.

Due to its dimensions, this aerosol dryer may not be suitable for all remote measurement sites. The shelter needs to be placed on a flat roof capable of carrying the weight of both the instrument and an operator. Furthermore, a compressor for the regenerating air needs sufficient three phase power supply. If these requirements for a deployment can be met, installation of such a dryer system will improve the comparability of measurements in an aerosol network.

Acknowledgements. The authors wish to thank all operators of the dryers at the sites for their contributions. We wish to acknowledge the skills of the mechanics in our mechanical workshop who helped to build the dryers.

Edited by: P. Laj

\section{References}

Baltensperger, U., Barrie, L., Fröhlich, C., Gras, J., Jäger, H., Jennings, S. G., Li, S. M., Ogren, J., Wiedensohler, A., Wehrli, C., and Wilson, J.: WMO/GAW aerosol measurement procedures, guidelines and recommendations. World Meteorological Organization Global Atmosphere Watch No. 153 (September 2003) WMO TD No. 1178, 2003.

Baron, P. A. and Willeke, K.: Aerosol Measurement, 2nd Edition, J. Wiley and Sons, 170-178, 2001.

Bergin, M. H., Ogren, K. O., Schwartz, S., and McInnes. L.: Evaporation of Ammonium Nitrate Aerosol in a Heated Nephelometer: Implications for Field Measurements Environ. Sci. Technol, 31, 2878-2883, 1997.

Birmili W., Stratmann, F., and Wiedensohler, A.: Design of a DMAbased size spectrometer for a large particle size range and stable operation, J. Aerosol Sci., 30, 549-553, 1999. 
Charron, A., Harrison, R.M., Moorcroft, S., and Booker, J.: Potential for simultaneous measurement of $\mathrm{PM}_{10}, \mathrm{PM}_{2.5}$ and $\mathrm{PM}_{1}$ for air quality monitoring purposes using a single TEOM, Atmos. Environ., 38, 21, 3453-3458, 2004.

Cyrys, J., Dietrich, G., Kreyling, W., Tuch, T., and Heinrich, J.: $\mathrm{PM}_{2.5}$ measurements in ambient aerosol: comparison between Harvard impactor (HI) and the tapered element oscillating microbalance (TEOM) system, Sci. Tot. Environ., 278(1-3), 191197, 2001.

Mozurkewich, M.: Aerosol Growth and the Condensation Coefficient for Water: A Review, Aerosol Sci. Technol., 5(2), 223-236, 1986.
Ten Brink, H. M., Khlystov, A., Kos, G. A. P., Tuch, T., Roth, C., and Kreyling, W.: A high-flow humidograph for testing the water uptake by ambient aerosol, Atmos. Environ., 34(25), 4291-4300, 2001.

Wex, H., Kiselev, A., Ziese, M., and Stratmann, F.: Calibration of LACIS as a CCN detector and its use in measuring activation and hygroscopic growth of atmospheric aerosol particles, Atmos. Chem. Phys., 6, 4519-4527, 2006, http://www.atmos-chem-phys.net/6/4519/2006/. 